\title{
Antibiotic Prescribing Rate in Lebanese Community Pharmacies: A Nationwide Patient-Simulated Study of Acute Bacterial Rhinosinusitis
}

\author{
Sally G. Yaacoub ${ }^{1, *}$, , Nathalie A. Lahoud ${ }^{1,2,3,4}$, Nicole J. Francis ${ }^{1}$, Deema W. Rahme ${ }^{5}$, Tony H. Murr ${ }^{6}$, \\ Patrick F. Maison ${ }^{2,7,8,9, \uparrow}$, Nadine G. Saleh ${ }^{1,2,3,4, \uparrow}$ \\ ${ }^{1}$ Faculty of Public Health, Lebanese University, Fanar, Lebanon \\ ${ }^{2}$ CERIPH, Center for Research in Public Health - Pharmacoepidemiology Surveillance Unit, Faculty of Public Health, Lebanese University, Fanar, Lebanon \\ ${ }^{3}$ INSPECT-LB: Institut National de Sante Publique, Epidemiologie Clinique et Toxicologie, Faculty of Public Health, Lebanese University, Fanar, Lebanon \\ ${ }^{4}$ Faculty of Pharmacy, Lebanese University, Hadat, Lebanon \\ ${ }^{5}$ Pharmacy Practice Department, Faculty of Pharmacy, Beirut Arab University, Beirut, Lebanon \\ ${ }^{6}$ Department of Medicine, Middle East Institute of Health, Bsalim, Lebanon \\ ${ }^{7}$ Direction de la Surveillance, ANSM, F-93100 Saint Denis, France \\ ${ }^{8} I S T-P E$, CHIC, F-94000 Créteil, France \\ ${ }^{9}$ EA 7379 EpidermE, Université Paris-Est Créteil, UPEC, Créteil F-94010, France
}

\section{ARTICLE INFO}

\section{Article History}

Received 4 July 2018

Accepted 3 January 2019

Keywords

Antibiotics

antimicrobial resistance

bacterial rhinosinusitis

community pharmacists

\begin{abstract}
This study aims to evaluate the antibiotic prescribing rate for acute bacterial rhinosinusitis in community pharmacies and to study the corresponding attitude and behavior of participants. A cross-sectional, nationwide study was conducted using a patient-simulated case of bacterial rhinosinusitis. Descriptive data were reported for the medications prescribed, questions asked, and recommendations made. Bivariate analysis was conducted to identify factors affecting the aforementioned. Out of the 250 community pharmacies visited, 77 (30.8\%) prescribed antibiotics, $15(6 \%)$ referred the patient to a physician, and 79 (32\%) made the right diagnosis. Amoxicillin/clavulanic acid (69.7\%) was the most prescribed antibiotic. The majority of the participants prescribed antibiotics according to guidelines. Overall, 108 (43.2\%) participants questioned about symptoms and few questioned about patient age, pregnancy, and history of rhinosinusitis. None counseled about interactions or in case a dose is missed. We concluded that antibiotics are easily prescribed in Lebanese community pharmacies. This misuse should be tackled by legislative authorities to restrict such practices.
\end{abstract}

(C) 2019 Atlantis Press International B.V.

This is an open access article distributed under the CC BY-NC 4.0 license (http://creativecommons.org/licenses/by-nc/4.0/).

\section{INTRODUCTION}

The global public health is threatened by antimicrobial resistance [1]. It has multiple causes, which are all under the umbrella of antibiotic overuse and misuse that is the "main driver" of resistance according to the Centers for Disease Control and Prevention (CDC) [2]. In addition to antibiotic overuse, resistance burden is summarized by: inappropriate prescribing, extensive agricultural use, and availability of few new antibiotics [3]. Several practices account for inappropriate antibiotic use such as physicians' suboptimal prescribing practices, patients' demand for antibiotics and self-medication, and pharmacists' delivery of antibiotics without medical prescriptions in community pharmacies [4-6]. A great interest is in the practice of community pharmacists regarding antibiotic dispensing and prescribing. It is specifically of main concern as many patients first consult their community pharmacist when suffering from symptoms of common infections, mainly

"Corresponding author. Email: Sally.yaacoub@gmail.com

${ }^{+}$These two authors contributed equally to this study.

${ }^{\ddagger}$ Present address: Doctoral School of Public Health, Paris-Est University, Créteil, France respiratory symptoms such as those of rhinosinusitis. The contribution of community pharmacists to antibiotic misuse and consequently resistance has been documented. In India, the estimated cost of antibiotics dispensed by pharmacies is approximately US \$1.1-1.7 billion [7]. The major misuse of community pharmacists is antibiotic prescribing, together with inadequate quality of prescribing and counseling. According to the CDC, pharmacists often prescribe antibiotics in common infections, such as rhinosinusitis. Optimally, when pharmacists are presented with a case of rhinosinusitis, they should prescribe over-the-counter medications for symptomatic relief and/or refer the patient to a physician, based on their clinical judgment and on the severity of the case. Specifically, $98 \%$ of acute rhinosinusitis cases are viral and do not require an antibiotic [2]. Although dispensing antibiotics without a medical prescription, nonetheless the prescribing of antibiotics, is prohibited by laws, it is still evident in many countries such as Jordan, Saudi Arabia, Brazil, Greece, and Spain [8-12]. In Lebanon, this law exists, but it is not implemented [13]. Thus, it is essential to conduct a patient-simulated study to assess the true rate of antibiotic prescribing in community pharmacies. 
The objective of our study is to evaluate the prescribing rate of antibiotics for acute bacterial rhinosinusitis in the community pharmacy setting and to study the behavior and attitude of the participant (pharmacist/assistant) in response to this case.

\section{MATERIALS AND METHODS}

\subsection{Study Design and Period}

This observational cross-sectional patient-simulated study was conducted between February 2017 and October 2017.

\subsection{Sampling}

A sample from all community pharmacies operating across Lebanon (a list of all pharmacies was obtained from the Order of Pharmacists of Lebanon) was randomly selected. Lebanon was stratified into its six distinct provinces (Beirut, Mount Lebanon, North Lebanon, South Lebanon, Bekaa, and Nabatiyeh) as presented in Table 1. Then, based on the proportion of pharmacies within each province, random sampling was done to obtain a representative sample of Lebanese community pharmacies. Using Epi Info version 7.0 (Centers for Disease Control and Prevention, Atlanta, GA, USA) for population survey, a sample of 250 community pharmacies was needed, where the overall rate of antibiotic prescription for infectious diseases such as rhinosinusitis and urinary tract infections was 77\%, which was obtained from an analogous study done in Saudi Arabia [9]. A margin of error of $\pm 5 \%$ and a confidence level of $95 \%$ was used.

\subsection{Data Collection and Case Scenario}

Two investigators (SY and NF), who are pharmacists, were responsible for data collection. Both entered each designated community pharmacy. The investigator (SY) would present the scenario (described below) of a case of acute rhinosinusitis to the pharmacist. The same investigator would proceed with the case presentation in order to eliminate any heterogeneity. The other investigator (NF) would only be an observer to help with the recall of data.

SY addressed the participants as follows: "Hello, are you the pharmacist?" Once the pharmacist was identified, SY would proceed: "My sister, at home, is suffering from severe facial pressure and a congested nose, what do I get her?" When the pharmacist was not available, the encounter was held with the pharmacy assistant. Any additional information was provided from a standardized case, only in response to the participants' questions. This standardized

Table 1 Distribution of pharmacies in Lebanese provinces

\begin{tabular}{lc}
\hline Province & Pharmacies, $\boldsymbol{N}(\%)$ \\
\hline Beirut & $232(7.8)$ \\
Mount Lebanon & $1289(43.4)$ \\
North Lebanon & $431(14.5)$ \\
South Lebanon & $343(11.6)$ \\
Nabatiyeh & $210(7)$ \\
Bekaa & $463(15.6)$ \\
Total & $2968(100)$ \\
\hline
\end{tabular}

case stemmed from recent Infectious Diseases Society of America (IDSA) guidelines for acute bacterial rhinosinusitis [14]. (1) Patient information: 25-year-old nonpregnant nonlactating female. (2) Chief complaint: severe facial pressure and nasal congestion. (3) History of present illness: symptoms of fever $\left(\geq 39^{\circ} \mathrm{C}\right)$, headache, facial pressure, nasal congestion, and cough that started 2 days ago. She is taking acetaminophen to manage her pain. (4) History: not on any chronic medications, and has no comorbidities and no allergies.

The investigators would avoid buying the medications by claiming that the medications were already found at home, or that approval from the patient (sister) was needed.

\subsection{Checklist}

After the encounter between the investigators and participant (pharmacist/assistant), a checklist about the response and questions asked, developed for the purpose of this study, was directly filled with the joined efforts of both investigators. The checklist included three major parts:

1. Pharmacy demographics and personnel

a. Location of the pharmacy

b. Participant (pharmacist or assistant)

c. Sex of the participant

2. Questions asked (if asked about the following: yes/no):

a. Patient information

- Age

- Allergy

- Chronic illnesses

- Chronic medications

- Pregnancy

- Lactation

b. Disease-related information

- Symptoms

- Onset and duration

- History of previous rhinosinusitis

- Risk factors

- Home management of current symptoms

3. Treatment and counseling

a. Diagnosis

b. Medications prescribed

- Name

- Dose

- Frequency

- Duration

- Expected action

- Side effects

- Food/drug-drug interactions

- Missed dose

c. Referral to a physician

d. Nonpharmacological recommendations 


\subsection{Statistical Analyses}

Descriptive analyses were done using frequencies (percentages) or medians [interquartile range (IQR)] for qualitative or quantitative variables, respectively, such as sociodemographic characteristics, participant's prescribing and counseling behavior, and the conformity of the management with the guidelines. Bivariate analyses were done using Pearson chi-square test or Fisher's exact test for the comparison of percentages and Student $t$-test or Kruskal-Wallis test for the comparison of means. Bivariate analyses were performed to study the association between antibiotic prescribing and the sociodemographic characteristics, diagnoses, and questions asked. All data analyses were performed using IBM SPSS Statistics for Windows, Version 21.0 (IBM Corp., Armonk, NY, USA), and a $p$-value of $<0.05$ was deemed statistically significant.

\section{RESULTS}

\subsection{Description of the Study Population}

A total of 250 pharmacies from all six provinces of Lebanon were visited. The sociodemographic characteristics of our sample are summarized in Table 2.

\subsection{Medication Prescribing and Referral}

After presenting our case, 15 (6\%) participants referred the patient to a physician. Overall, the rate of antibiotic prescribing was $30.8 \%$. Amoxicillin/clavulanic acid was the most prescribed antibiotic (69.7\%). Participants also prescribed levofloxacin, cefuroxime, cefixime, azithromycin, and amoxicillin in decreasing order. The medications prescribed, either alone or as adjunctive treatment to antibiotics, include anti-inflammatory agents, decongestants, antihistamines, corticosteroids, or a combination. The medications prescribed by the participants are detailed in Table 3. In cases where the participants' diagnoses were bacterial rhinosinusitis, $30(69.8 \%)$ prescribed a first-line antibiotic, according to the IDSA guidelines [2,14]. Overall, only five (2\%) and four (1.6\%) participants prescribed a wrong dose and a wrong duration, respectively.

Table 2 Sociodemographic characteristics of the sampled pharmacies $(N=250)$

\begin{tabular}{lc}
\hline Sociodemographic characteristics & $\boldsymbol{N}(\%)$ \\
\hline Sex & \\
Male & $143(57.2)$ \\
Female & $107(42.8)$ \\
Participant & \\
Pharmacist & $179(71.6)$ \\
Assistant & $71(28.4)$ \\
Location of the pharmacy & \\
Beirut & $20(7.8)$ \\
Mount Lebanon & $109(43.4)$ \\
North Lebanon & $36(14.5)$ \\
South Lebanon & $29(11.6)$ \\
Nabatiyeh & $17(7)$ \\
Bekaa & $39(15.6)$ \\
\hline
\end{tabular}

Table 3 Medications prescribed by the participants

\begin{tabular}{|c|c|}
\hline & $N(\%)$ \\
\hline Antibiotics & $77(100)$ \\
\hline Amoxicillin $875 \mathrm{mg}$ and clavulanic acid $125 \mathrm{mg}$ & $53(68.8)$ \\
\hline Amoxicillin $500 \mathrm{mg}$ & $1(1.3)$ \\
\hline Cefuroxime $500 \mathrm{mg}$ & $6(7.8)$ \\
\hline Cefixime $400 \mathrm{mg}$ & $4(5.2)$ \\
\hline Azithromycin $250 \mathrm{mg}$ & $3(3.9)$ \\
\hline Levofloxacin $500 \mathrm{mg}$ & $10(13)$ \\
\hline Other medications & $250(100)$ \\
\hline Anti-inflammatory agents & $16(6.4)$ \\
\hline Ibuprofen $400 \mathrm{mg}$ & $11(4.4)$ \\
\hline Diclofenac potassium $50 \mathrm{mg}$ & $3(1.2)$ \\
\hline Aceclofenac $100 \mathrm{mg}$ & $2(0.8)$ \\
\hline Oral analgesics and decongestants & $58(23.2)$ \\
\hline Ibuprofen $200 \mathrm{mg}$ + Pseudoephedrine $30 \mathrm{mg}$ & $36(14.4)$ \\
\hline $\begin{array}{l}\text { Acetaminophen } 500 \mathrm{mg}+\text { Phenylephrine } 10 \mathrm{mg}+ \\
\text { Ascorbic acid } 40 \mathrm{mg}\end{array}$ & $14(5.6)$ \\
\hline $\begin{array}{l}\text { Acetaminophen } 500 \mathrm{mg}+\text { Pseudoephedrine } 60 \mathrm{mg}+ \\
\text { Chlorphenamine } 4 \mathrm{mg}\end{array}$ & $8(3.2)$ \\
\hline Oral antihistamines & $16(6.4)$ \\
\hline Desloratadine $5 \mathrm{mg}$ & $14(5.6)$ \\
\hline Fexofenadine $180 \mathrm{mg}$ & $2(0.8)$ \\
\hline Oral antihistamines and decongestants & $57(22.8)$ \\
\hline Loratadine $5 \mathrm{mg}$ + Pseudoephedrine sulfate $120 \mathrm{mg}$ & $35(14)$ \\
\hline Desloratadine $2.5 \mathrm{mg}+$ Pseudoephedrine sulfate $120 \mathrm{mg}$ & $22(8.8)$ \\
\hline Nasal antihistamines & $2(0.8)$ \\
\hline Azelastine $\mathrm{HCl} 0.4 \mathrm{mg}$ & $2(0.8)$ \\
\hline Nasal decongestants & $75(30)$ \\
\hline Xylometazoline $\mathrm{HCl} 0.1 \%$ & $59(23.6)$ \\
\hline Xylometazoline $\mathrm{HCl}$ 0.1\% + Carbocysteine $10 \%$ & $9(3.6)$ \\
\hline Phenylephrine $2.5 \%$ + Dimethindene maleate $0.25 \%$ & $7(2.8)$ \\
\hline Nasal corticosteroids & $39(15.6)$ \\
\hline Triamcinolone acetonide $55 \mu \mathrm{g}$ & $3(1.2)$ \\
\hline Mometasone furoate $50 \mu \mathrm{g}$ & $31(12.4)$ \\
\hline Fluticasone propionate $50 \mu \mathrm{g}$ & $3(1.2)$ \\
\hline Beclometasone dipropionate $100 \mu \mathrm{g}$ & $2(0.8)$ \\
\hline
\end{tabular}

\subsection{Diagnosis as Reported by Participants}

The participants asked between 0 and 15 questions with a median of one question (IQR = 0-2). Out of 250 participants, $105(42 \%)$ asked no questions at all, whereas only one (0.4\%) asked 15 questions. None of the participants asked about chronic medications, and only one asked about chronic illnesses or comorbidities (chronic allergy). From the participants, 49 (19.6\%) asked about age, eight $(3.2 \%)$ asked about drug allergies, five (2\%) asked about pregnancy, and two (0.8\%) asked about lactation. Additionally, 108 (43.2\%) participants asked about at least one of the rhinosinusitis symptoms (such as sore throat, cough, and fever), 53 (21.2\%) inquired about the onset of symptoms, and 26 (10.4\%) inquired about the history of sinusitis symptoms. For the diagnosis, 79 (32\%) participants correctly diagnosed the case as bacterial rhinosinusitis, and the rest diagnosed the case as seasonal allergy, allergic rhinosinusitis, or flu, as shown in Figure 1.

\subsection{Counseling and Recommendations}

None of the participants explained any drug-food or drug-drug interactions and none mentioned the actions that should be taken in case a dose is missed. Twenty-six (10.4\%) participants explained the expected actions of the medications prescribed, whereas only 
one mentioned stomach upset as a side effect. Recommendations in case the symptoms persist were to take an antibiotic (10.4\%) or to seek a physician $(10.4 \%)$. Saline nasal spray was the main nonpharmacological recommendation given by the participants.

\subsection{Prescribing Antibiotics}

The association between the antibiotic prescribing rate and the sociodemographic characteristics and diagnoses is presented in Table 4. The association between the diagnosis reported and antibiotic prescribing was statistically significant $(p<0.001)$. Also, the highest prescribing rate of antibiotic was reported in Beirut province.

The diagnosis did not significantly differ between males and females, pharmacists and assistants, or pharmacy locations. In addition, those who asked about the presence of sputum, facial pressure,

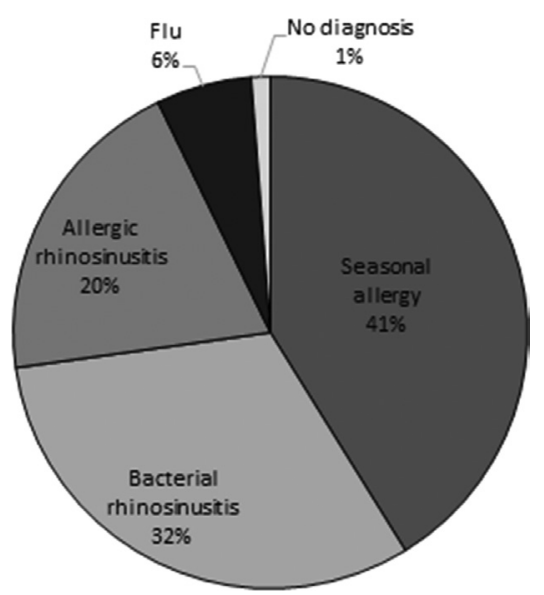

Figure 1 Case diagnoses as reported by participants $(N=250)$.

Table 4 Antibiotic prescribing rate based on the sociodemographic characteristics and diagnosis

\begin{tabular}{|c|c|c|c|}
\hline & $\begin{array}{l}\text { ATB (\%) } \\
(N=77)\end{array}$ & $\begin{array}{c}\text { No ATB (\%) } \\
\quad(N=173)\end{array}$ & $p$ \\
\hline \multicolumn{4}{|c|}{ Sociodemographic characteristics } \\
\hline \multicolumn{4}{|c|}{ Sex } \\
\hline Male & $44(30.8)$ & $99(69.2)$ & \multirow[t]{2}{*}{0.990} \\
\hline Female & $33(30.8)$ & $74(69.2)$ & \\
\hline \multicolumn{4}{|l|}{ Participant } \\
\hline Pharmacist & $52(29.1)$ & $127(70.9)$ & \multirow[t]{2}{*}{0.341} \\
\hline Assistant & $25(35.2)$ & $46(64.8)$ & \\
\hline \multicolumn{4}{|l|}{ Location of the pharmacy } \\
\hline Beirut & $13(65.0)$ & $7(35.0)$ & \multirow{6}{*}{$<0.001^{\star}$} \\
\hline Mount Lebanon & $24(22.0)$ & $85(78.0)$ & \\
\hline North Lebanon & $16(44.4)$ & $20(55.6)$ & \\
\hline South Lebanon & $12(41.4)$ & $17(58.6)$ & \\
\hline Nabatiyeh & $5(29.4)$ & $12(70.6)$ & \\
\hline Bekaa & $7(17.9)$ & $32(82.1)$ & \\
\hline \multicolumn{4}{|l|}{ Diagnosis reported } \\
\hline No diagnosis & 0 & $3(100)$ & \multirow{5}{*}{$0.001^{*}$} \\
\hline Seasonal allergy & $6(5.9)$ & $96(94.1)$ & \\
\hline Bacterial rhinosinusitis & $44(55.7)$ & $35(44.3)$ & \\
\hline Allergic rhinosinusitis & $25(50)$ & $25(50)$ & \\
\hline Flu & $2(12.5)$ & $14(87.5)$ & \\
\hline
\end{tabular}

"Statistically significant; ATB, antibiotics. fever, or history of rhinosinusitis had a statistically significant higher antibiotic prescribing rate than those who did not, as shown in Table 5. By contrast, those who asked about the onset of symptoms had a statistically lower antibiotic prescribing rate than those who did not. Moreover, there was a significant difference in the antibiotic prescribing rates depending on the number of questions asked.

\section{DISCUSSION}

Our study evaluated the true antibiotic prescribing rate for a bacterial rhinosinusitis case in the Lebanese community pharmacy setting. Based on the results obtained, we detected that, although

Table 5 Antibiotic prescribing rate based on the questions asked

\begin{tabular}{|c|c|c|c|}
\hline Questions & $\begin{array}{l}\text { ATB (\%) } \\
(N=77)\end{array}$ & $\begin{array}{c}\text { No ATB (\%) } \\
\quad(N=173)\end{array}$ & $p$ \\
\hline \multicolumn{4}{|l|}{ Sore throat } \\
\hline Yes & $16(40)$ & $24(60)$ & \multirow[t]{2}{*}{0.169} \\
\hline No & $61(29)$ & $149(71.0)$ & \\
\hline \multicolumn{4}{|l|}{ Fatigue } \\
\hline Yes & $6(50)$ & $6(50)$ & \multirow[t]{2}{*}{0.197} \\
\hline No & $71(29.8)$ & $167(70.2)$ & \\
\hline \multicolumn{4}{|l|}{ Cough } \\
\hline Yes & $12(50)$ & $12(50)$ & \multirow[t]{2}{*}{$0.032^{*}$} \\
\hline No & $65(28.8)$ & $161(71.2)$ & \\
\hline \multicolumn{4}{|l|}{ Sputum } \\
\hline Yes & $5(71.4)$ & $2(28.6)$ & \multirow[t]{2}{*}{$0.030^{*}$} \\
\hline No & $72(29.6)$ & $171(70.4)$ & \\
\hline \multicolumn{4}{|c|}{ Color of sputum } \\
\hline Yes & $4(66.7)$ & $2(33.3)$ & \multirow[t]{2}{*}{0.075} \\
\hline No & $73(29.9)$ & $171(70.1)$ & \\
\hline \multicolumn{4}{|c|}{ Nasal congestion } \\
\hline Yes & $7(46.7)$ & $8(53.3)$ & \multirow[t]{2}{*}{0.246} \\
\hline No & $70(29.8)$ & $165(70.2)$ & \\
\hline \multicolumn{4}{|c|}{ Facial pressure } \\
\hline Yes & $19(52.8)$ & $17(47.2)$ & \multirow[t]{2}{*}{$0.002^{\star}$} \\
\hline No & $58(27.1)$ & $156(72.9)$ & \\
\hline \multicolumn{4}{|l|}{ Headache } \\
\hline Yes & $7(33.3)$ & $14(66.7)$ & \multirow[t]{2}{*}{0.793} \\
\hline No & $70(30.6)$ & $159(69.4)$ & \\
\hline \multicolumn{4}{|l|}{ Fever } \\
\hline Yes & $39(65)$ & $21(35)$ & \multirow[t]{2}{*}{$<0.001^{\star}$} \\
\hline No & $38(20)$ & $152(80)$ & \\
\hline \multicolumn{4}{|c|}{ Onset of symptoms } \\
\hline Yes & $24(45.3)$ & $29(54)$ & \multirow[t]{2}{*}{$0.010^{*}$} \\
\hline No & $53(26.9)$ & $144(73.1)$ & \\
\hline \multicolumn{4}{|c|}{ History of rhinosinusitis } \\
\hline Yes & $14(53.8)$ & $12(46.2)$ & \multirow[t]{2}{*}{$0.007^{*}$} \\
\hline No & $63(28.1)$ & $161(71.9)$ & \\
\hline \multicolumn{4}{|c|}{ Number of questions } \\
\hline 0 & $15(14.3)$ & $90(85.7)$ & \multirow{10}{*}{$<0.001^{\star}$} \\
\hline 1 & $17(34)$ & $33(66)$ & \\
\hline 2 & $15(44.1)$ & $19(55.9)$ & \\
\hline 3 & $10(45.5)$ & $12(54.5)$ & \\
\hline 4 & $11(50)$ & $11(50)$ & \\
\hline 5 & $2(25)$ & $6(75)$ & \\
\hline 6 & $3(75)$ & $1(25)$ & \\
\hline 7 & $2(66.7)$ & $1(33.3)$ & \\
\hline 9 & $1(100)$ & 0 & \\
\hline 15 & $1(100)$ & 0 & \\
\hline
\end{tabular}

"Statistically significant; ATB, antibiotics. 
illegal, community pharmacists prescribe antibiotics and dispense them without a medical prescription for bacterial rhinosinusitis.

Our results are similar to those of a cross-sectional study conducted by Farah et al. [15] to subjectively assess antibiotic dispensing without a medical prescription in Lebanon, which reports that $32 \%$ of the pharmacists dispense antibiotics without a prescription. The results reported in the present study show a similar rate of antibiotic prescribing to that self-reported by pharmacists [15]. Although there are no previous studies conducted in Lebanon using the patient-simulated method, the antibiotic prescribing rate was found to be lower when compared with that in other countries. In a study performed in Saudi Arabia, $40 \%$ of the pharmacists prescribed an antibiotic in response to a case of bacterial rhinosinusitis [9]. In Jordan, a prescribing rate of $48.5 \%$ was reported for the same case [8]. In Brazil, a similar study showed that $56 \%$ of the pharmacists offered antibiotics for bacterial rhinosinusitis [10]. Finally, in Greece, 69\% of pharmacists prescribed antibiotics for high fever rhinosinusitis [16]. It is possible that the rate of antibiotic prescribing would have been higher in the present case if the patient insisted on having an antibiotic. Some of the common factors that contribute to this antibiotic prescribing phenomenon include the country's regulations, education and knowledge, and practice trends.

Additionally, the majority of the participants did not refer the patient to a physician, although bacterial rhinosinusitis can be of different etiologies and severity. The reasons for pharmacists not referring the patient and thus giving their own diagnosis and treatment are the underestimation of the physician's qualifications and the overestimation of their own knowledge [17]. This rate is higher than that reported for simulated cases in Jordan, where the referral rate was only $4 \%$ [8]. Participants had neither enough information nor the necessary tools to diagnose this case.

Some participants misdiagnosed the case as seasonal allergy or allergic rhinosinusitis. Thus, antihistamines were prescribed, although they are contraindicated in case of bacterial rhinosinusitis [14]. The rate of bacterial rhinosinusitis diagnosis reported is considered low compared with that of seasonal allergy. Many factors could explain this rate such as the timing of the data collection (end of February/beginning of March). This time of year marks the beginning of spring, which stimulates allergies. Reasons for misdiagnosing also include lack of training, lack of up-to-date knowledge, and presence of symptoms similar to other conditions (e.g., flu and allergy) [18]. As for the questions asked, in the present study, the visits were performed in the afternoon on weekdays or all day on Sundays, which could have had an effect on the participants' interaction. It is believed that individuals working shifts on Sundays or midafternoons may exert lower levels of discretionary effort and productivity [19]. A study in Spain [20] showed similar results for asking about allergies and possible pregnancy while prescribing antibiotics. Pharmacists did not ask about allergies in $73.9 \%$ of cases and never asked about possible pregnancy [20]. Similarly, in India, none of the pharmacies queried about potential drug allergies as reported in a similar study [7].

Pharmacists play a very important role in counseling the patient about medication use and giving recommendations regarding side effects or nonpharmacological treatment. Counseling the patient can lead to a decrease in medical errors and misuse, increase compliance of the patient to therapy, and improve clinical and economic outcomes, quality of life, knowledge, and patient's satisfaction [21,22]. The majority of participants did not mention any counseling points or recommendations. The results are in concordance with a study conducted in Ethiopia. The findings were that the information provided on what to do when a dose is missed (100\%), contraindications (95.2\%), and the importance of compliance or adherence $(92.9 \%)$ were the most commonly ignored types of information [23]. This can be attributed to the fact that some pharmacists counsel the patients after purchasing the medications. Another explanation for not counseling is that pharmacists believe that too much information could confuse the patient and that it should be done for new drugs on the market [24,25].

Symptoms such as fever and facial pressure are indicative of bacterial rhinosinusitis, which explains their association with a higher antibiotic prescribing rate. The antibiotic prescribing rate in Beirut was significantly higher, which can be related to the proximity of pharmacies found in this smaller province compared with other provinces. Participants might adopt practices such as increased antibiotic prescribing to gain competitive edge over rivals in this province, in hopes of gaining a new patient or "customer."

In this study, $29 \%$ of the included participants were pharmacy assistants evaluating the case, diagnosing, and prescribing medications. The similarity between the antibiotic prescribing rates of the assistants to that of the pharmacists' is alarming. These practices may be attributed to the confidence of the assistants to prescribe medications, the training and instructions of the pharmacists to the assistants, the authority given to them by the pharmacists, and the lack of regulation enforcement that prohibits antibiotic prescribing in community pharmacists.

The strengths of this study include the innovativeness. To our knowledge, this is the first study to determine the true antibiotic prescribing rate in community pharmacies using an objective method rather than a subjective one. It is nationwide and representative of Lebanese community pharmacies. Moreover, the case scenario written was derived from the definition, symptoms, and risk factors of acute bacterial rhinosinusitis. To ensure the objectivity of the case scenario and to eliminate any bias or influence on the participant to prescribe an antibiotic, the case scenario was practiced multiple times beforehand. Finally, the same investigator (SY) proceeded with the presentation of the case in order to eliminate any heterogeneity, whereas the other investigator (NF) only observed to help with the recall of data.

However, this study has several limitations. The sociodemographic characteristics (e.g., education, years of experience, age, owner or employee) of the participants were not available; thus, the factors that affect antibiotic prescribing could not be studied. Furthermore, there was no evidence to ensure that the participants were exactly who they said they were; it is possible that some were assistants who claimed to be pharmacists. Finally, it was not possible to distinguish between participants who made the right diagnosis based on the right questions from those who based it on irrelevant questions-thus, leading to overestimation of the rate of reporting a right diagnosis.

In the future, it would be interesting to perform a patient-simulated study where the investigator asks the participants questions about drug utilization, diagnosis, and educational background, to assess the contributing factors to their practice. 


\section{CONCLUSION}

In a representative sample of community pharmacies, we concluded that antibiotics can be easily prescribed and dispensed without a medical prescription for acute bacterial rhinosinusitis. The practices documented should urge the Order of Pharmacists of Lebanon and the Ministry of Public Health to take action and implement the laws that are already set: the law that prohibits the absence of a pharmacist in every functioning community pharmacy and the law that restricts the sale of antibiotics without a prescription. A more stringent application of these regulations will go a long way toward fighting back against the global threat of antimicrobial resistance.

\section{CONFLICTS OF INTEREST}

The authors declare that they have no conflicts of interest.

\section{ETHICAL STATEMENT}

The Lebanese University ethics committee waived the need for approval as the study was observational, anonymous, and respected the individuals' confidentiality. No audio or video recording was made and data was kept anonymous thus nondisclosure to pharmacists was considered ethically acceptable especially that it is a minimal risk study where the benefits outweigh the risks.

\section{REFERENCES}

[1] WHO. Antimicrobial resistance. WHO 2018. http://www.who.int/ mediacentre/factsheets/fs194/en/ (accessed February 25, 2018).

[2] Adult Treatment Recommendations $\mid$ Community|Antibiotic Use | CDC n.d. https://www.cdc.gov/antibiotic-use/community/for-hcp/ outpatient-hcp/adult-treatment-rec.html (accessed February 25, 2018).

[3] Ventola CL. The antibiotic resistance crisis. Pharm Ther 2015;40;277-83.

[4] Al-Azzam SI, Al-Husein BA, Alzoubi F, Masadeh MM, Al-Horani MA. Self-medication with antibiotics in Jordanian population. Int J Occup Med Environ Health 2007;20;373-80.

[5] Ochoa C, Eiros JM, Inglada L, Vallano A, Guerra L. Assessment of antibiotic prescription in acute respiratory infections in adults. J Infect 2000;41;73-83.

[6] Yagupsky P. Selection of antibiotic-resistant pathogens in the community. Pediatr Infect Dis J 2006;25;974-6.

[7] Shet A, Sundaresan S, Forsberg BC. Pharmacy-based dispensing of antimicrobial agents without prescription in India: appropriateness and cost burden in the private sector. Antimicrob Resist Infect Control 2015;4;55.

[8] Almaaytah A, Mukattash TL, Hajaj J. Dispensing of nonprescribed antibiotics in Jordan. Patient Prefer Adherence. 2015;9;1389-95.

[9] Bin Abdulhak AA, Al Tannir MA, Almansor MA, Almohaya MS, Onazi AS, Marei MA, et al. Nonprescribed sale of antibiotics in
Riyadh, Saudi Arabia: a cross sectional study. BMC Public Health 2011;11;538.

[10] Volpato DE, de Souza BV, Dalla Rosa LG, Melo LH, Daudt CAS, Deboni L. Use of antibiotics without medical prescription. Braz J Infect Dis 2005;9;288-91.

[11] Plachouras D, Kavatha D, Antoniadou A, Giannitsioti E, Poulakou G, Kanellakopoulou K, et al. Dispensing of antibiotics without prescription in Greece, 2008; another link in the antibiotic resistance chain. Euro Surveill 2010;15;pii: 19488.

[12] Llor C, Monnet D, Cots J. Small pharmacies are more likely to dispense antibiotics without a medical prescription than large pharmacies in Catalonia, Spain. Euro Surveill 2010;15; pii: 19635 .

[13] Ministry of Public Health. Decision number 1/2636. 2015. http:// www.moph.gov.lb/en/laws\#/Laws/view/19

[14] Chow AW, Benninger MS, Brook I, Brozek JL, Goldstein EJC, Hicks LA, et al. IDSA clinical practice guideline for acute bacterial rhinosinusitis in children and adults. Clin Infect Dis 2012;54;e72-e112.

[15] Farah R, Lahoud N, Salameh P, Saleh N. Antibiotic dispensation by Lebanese pharmacists: a comparison of higher and lower socio-economic levels. J Infect Public Health 2015;8;37-46.

[16] Contopoulos-Ioannidis DG, Koliofoti ID, Koutroumpa IC, Giannakakis IA, Ioannidis JPA. Pathways for inappropriate dispensing of antibiotics for rhinosinusitis: a randomized trial. Clin Infect Dis 2001;33;76-82.

[17] Caamaño F, Tomé-Otero M, Takkouche B, Gestal-Otero JJ. Influence of pharmacists' opinions on their dispensing medicines without requirement of a doctor's prescription. Gac Sanit 2005;19;9-14.

[18] The Reasons Why Misdiagnosis Occurs. n.d. http://www.clackamaslawoffice.com/the-reasons-why-misdiagnosis-occurs/ (accessed February 25, 2018).

[19] Bryson A, Forth J. Productivity and days of the week. 2007. https://eprints.lse.ac.uk/4963/ (accessed October 2017).

[20] Guinovart MC, Figueras A, Llor C. Selling antimicrobials without prescription - far beyond an administrative problem. Enferm Infecc Microbiol Clin 2018;36;290-2.

[21] Nkansah N, Mostovetsky O, Yu C, Chheng T, Beney J, Bond CM, et al. Effect of outpatient pharmacists' non-dispensing roles on patient outcomes and prescribing patterns. Cochrane Database Syst Rev 2010;CD000336.

[22] Okumura LM, Rotta I, Correr CJ. Assessment of pharmacist-led patient counseling in randomized controlled trials: a systematic review. Int J Clin Pharm 2014;36;882-91.

[23] Surur S, Getachew E, Teressa E, Hailemeskel B, Getaw NS, Erku DA. Self-reported and actual involvement of community pharmacists in patient counseling: a cross-sectional and simulated patient study in Gondar, Ethiopia. Pharm Pract (Granada) 2017; $15 ; 890$.

[24] Alaqeel S, Abanmy NO. Counselling practices in community pharmacies in Riyadh, Saudi Arabia: a cross-sectional study. BMC Health Serv Res 2015;15;557.

[25] Puspitasari HP, Aslani P, Krass I. Pharmacists' and consumers' viewpoints on counselling on prescription medicines in Australian community pharmacies. Int J Pharm Pract 2010;18;202-8. 